\title{
Waveguide Slot Array Antenna with a Hybrid-Phase Feed for Grating Lobe Reduction
}

\author{
Son Trinh-Van, ${ }^{1}$ Sung Chan Song, ${ }^{2}$ Seung-Hee Seo, ${ }^{3}$ and Keum Cheol Hwang ${ }^{1}$ \\ ${ }^{1}$ School of Electronic and Electrical Engineering, Sungkyunkwan University, Suwon 440-746, Republic of Korea \\ ${ }^{2}$ PGM Center, Hanwha Thales, Yongin 449-885, Republic of Korea \\ ${ }^{3}$ Agency for Defense Development, Daejeon 305-600, Republic of Korea \\ Correspondence should be addressed to Keum Cheol Hwang; khwang@skku.edu
}

Received 26 November 2015; Revised 22 January 2016; Accepted 24 January 2016

Academic Editor: Safieddin Safavi-Naeini

Copyright (C) 2016 Son Trinh-Van et al. This is an open access article distributed under the Creative Commons Attribution License, which permits unrestricted use, distribution, and reproduction in any medium, provided the original work is properly cited.

\begin{abstract}
The design of a 112-element millimeter-wave waveguide slot array antenna to reduce the grating lobe level is presented. A hybridphase feeding technique combining a cophase feed and an alternating-phase feed is applied to facilitate the suppression of grating lobes. In addition, a stepped feed waveguide and offset coupling slots aligned in a line are employed to realize a tapered aperture distribution. As a result, grating lobe suppression of $8.1 \mathrm{~dB}$ was achieved on the diagonal planes compared to a conventional alternating-phase-fed waveguide slot array antenna. A prototype of the proposed antenna was fabricated and measured. The measured results show that the proposed antenna exhibits a $-15 \mathrm{~dB}$ reflection bandwidth of $3.4 \%$ and an average realized gain of $26.72 \mathrm{dBi}$ within the measured frequency range. Good agreement between the simulated and measured radiation patterns is also observed.
\end{abstract}

\section{Introduction}

Waveguide slot array antennas have been excellent candidates for commercial and military applications in millimeter-wave frequency bands due to their advantages of high efficiency, high gain, and precise control of the aperture distribution [13]. A well-known and accurate design procedure for linear and planar arrays of the longitudinal slots on waveguides was developed by Elliott [4-6], taking into account external and internal mutual coupling effects. However, the resonant nature of the slots and the slot spacing of the halfguided wavelength reduce the usable operating bandwidth, especially when the number of slots increases [7]. Several techniques have been introduced to overcome this bandwidth limitation. In one study [8], wideband slot radiators or a subarraying technique in a feeding network was utilized to enhance the frequency bandwidth of the waveguide slot array, but the advantages are limited or the feeding network becomes complex. Alternating-phase-fed waveguide slot arrays were then proposed to implement broadband resonant characteristics $[9,10]$. This feeding scheme also removes the need for folded shorts because the shorting wall is located only one-quarter of a wavelength from the last slots in the feeding waveguide. Although the alternating-phase displacement displays more broadband characteristics, the slot arrays are associated with the disadvantage of exhibiting undesirable $-18 \mathrm{~dB}$ grating lobes on the diagonal planes [11].

In this paper, we propose a waveguide slot array antenna with suppressed grating lobes. A hybrid-phase feeding technique incorporating a cophase feed and an alternating-phase feed is utilized to reduce the grating lobes on the diagonal planes. The cophase feed is implemented in two center radiating waveguides, whereas the alternating-phase feed is applied to the others. In order to realize a tapered aperture distribution, a stepped feed waveguide with coupling slots which are aligned in a line is proposed and designed. The radiating slot data are obtained using Elliott's procedure, including internal higher mode coupling and external mutual coupling between the radiating slots. Details of the proposed waveguide slot array antenna and measurement results are presented and discussed in the following sections. 


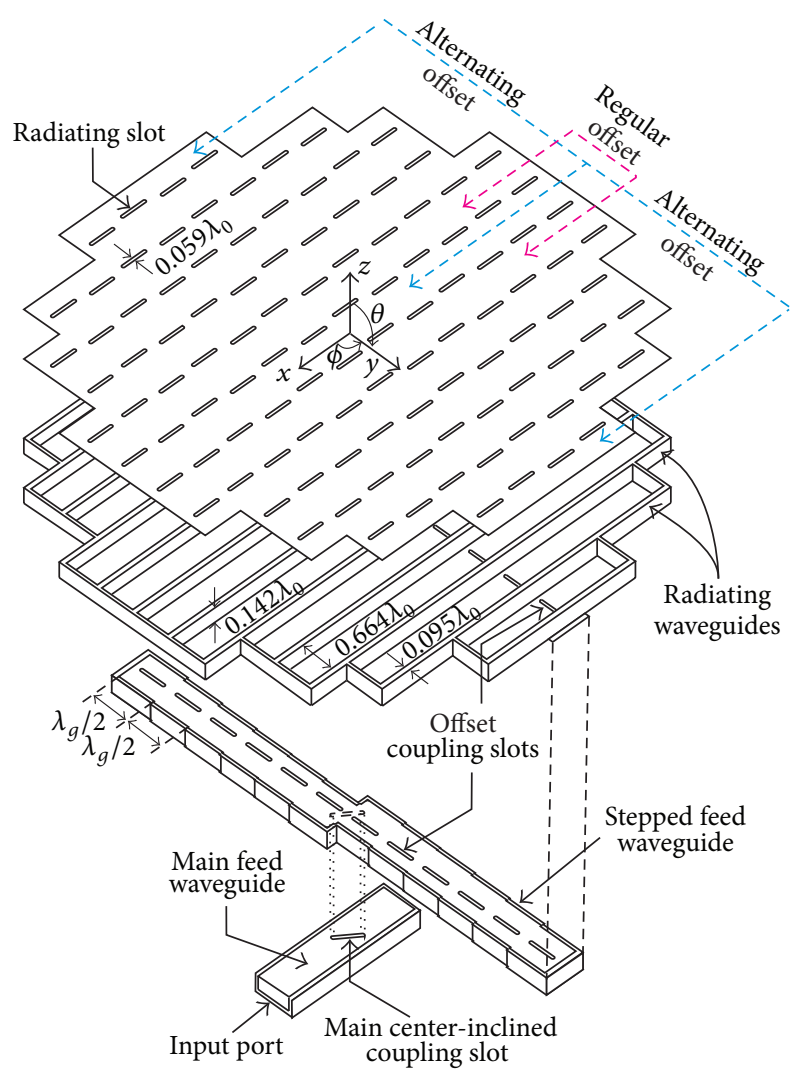

FIGURE 1: Geometry of the proposed 112-element waveguide slot array antenna.

\section{112-Element Waveguide Slot Array Antenna}

Figure 1 illustrates the geometry of the proposed 112-element waveguide slot array antenna employing the hybrid-phase feeding technique and the stepped feed waveguide. The hybrid-phase feed waveguide combines cophase feed and alternating-phase feed structures. The cophase feeding structure is implemented on two center radiating waveguides, and radiating slots on their broad walls are arranged in a regular offset configuration. For the remaining radiating waveguides, the alternating-phase feeding scheme is applied with the radiating slots on their broad walls arranged in an alternating offset configuration [11]. Each radiating waveguide is fed by an offset coupling slot on the broad wall of the feed waveguide. However, instead of using a straight feed waveguide and having the offset coupling slots arrayed on the broad wall, the absolute positions of the coupling slots in the proposed design are aligned in a straight line and the feed waveguide is divided into 12 segments. Each waveguide segment has a length of $\lambda_{g} / 2$ and is shifted from the aligned coupling slots, hence forming a stepped feed waveguide. The coupling power from the stepped feed waveguide to the radiating waveguides is determined by the offset value of each waveguide segment. Therefore, a tapered aperture distribution along the $y$-direction can be realized. A main center-inclined coupling slot is used to transmit

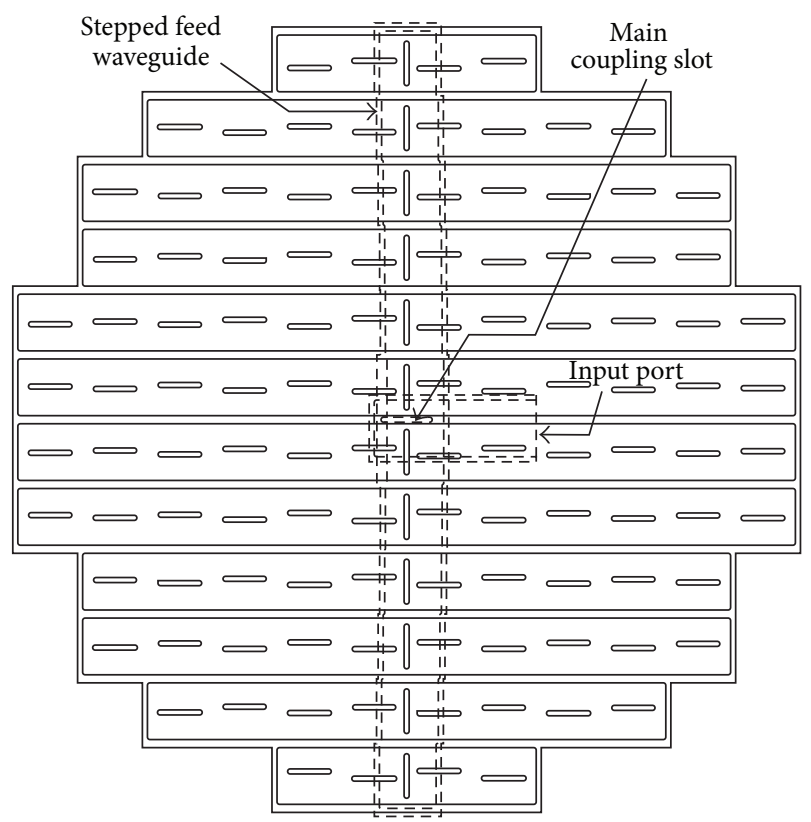

FIGURE 2: Geometry of the conventional alternating-phase-fed 112element waveguide slot array antenna.

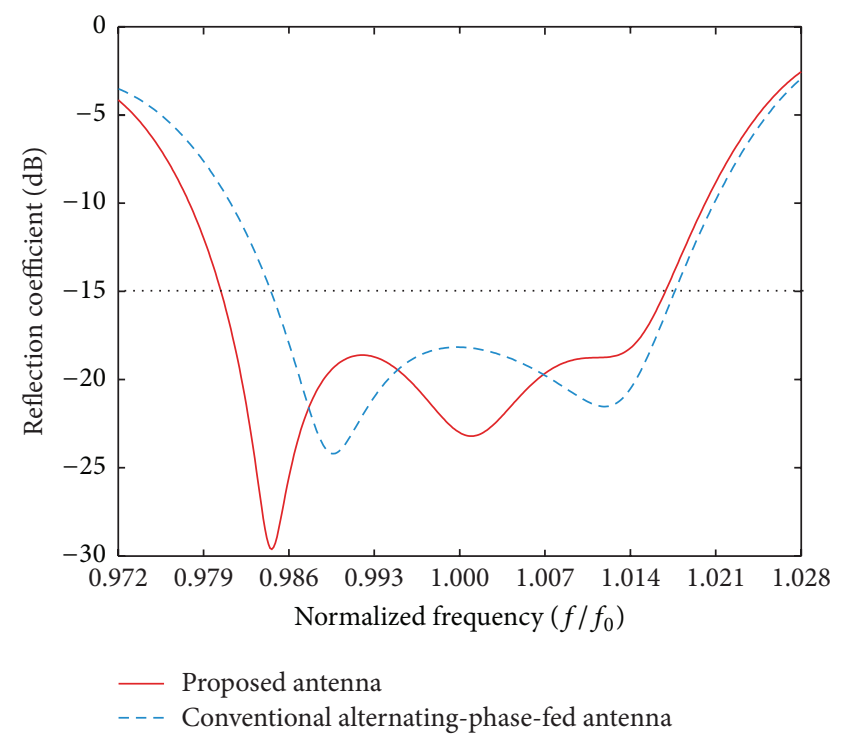

Figure 3: Comparison of simulated reflection coefficients between the proposed antenna and the conventional alternating-phase-fed antenna.

the input power from the main feed waveguide to the stepped feed waveguide. The radiating slot data are obtained using Elliott's procedure through an iterative process $[5,6]$. Internal higher mode coupling and external mutual coupling between the radiating slots were also considered in Elliott's design equations. All radiating slots and coupling slots have a width of $0.059 \lambda_{0}$. The rectangular waveguides have a width of $0.664 \lambda_{0}$ and a height of $0.142 \lambda_{0}$. All radiating waveguides are separated by a wall with a thickness of $0.095 \lambda_{0}$. Simulations 


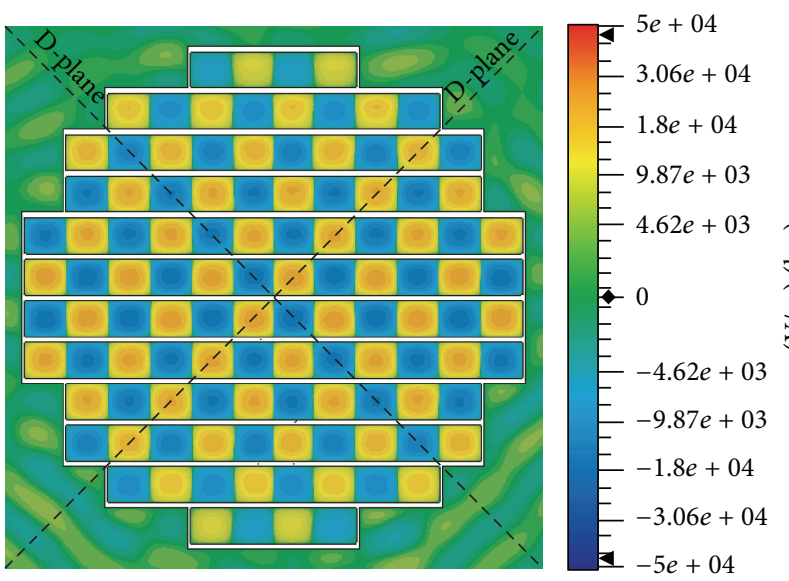

(a)

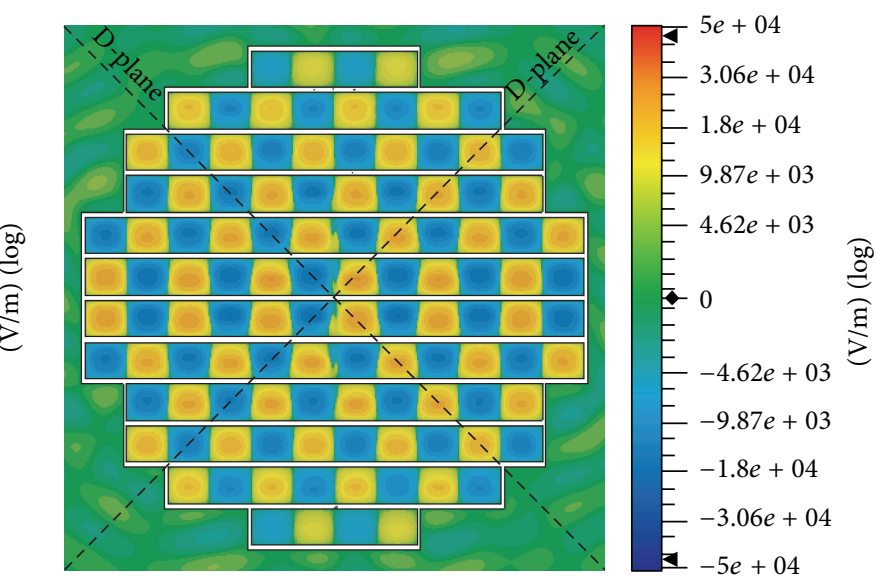

(b)

FIGURE 4: Simulated electric field distribution inside the radiating waveguides at the operating center frequency $f_{0}$ : (a) the conventional alternating-phase-fed antenna and (b) the proposed antenna.

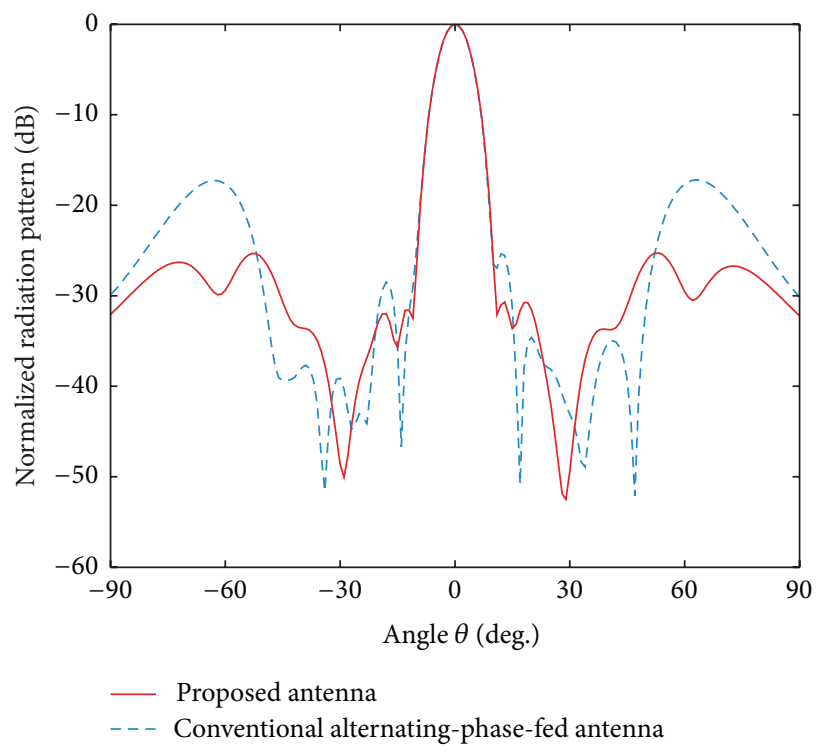

FIGURE 5: Comparison of simulated normalized radiation patterns at $f_{0}$ on the D-plane between the conventional alternating-phase-fed antenna and the proposed antenna.

are performed using the ANSYS High Frequency Structure Simulator (HFSS) based on the three-dimensional finite element method (FEM).

In order to demonstrate the feasibility of the proposed hybrid-phase feeding technique to reduce the grating lobe, a comparison with a waveguide slot array antenna fed by the conventional alternating-phase feed is conducted with Chebyshev aperture tapering of $25 \mathrm{~dB}$. Figure 2 shows the geometry of the conventional alternating-phase-fed 112element waveguide slot array antenna used for a comparison. The simulated reflection coefficients of the two antennas are shown in Figure 3. It is important to note that the proposed hybrid-phase feed enhances the $-15 \mathrm{~dB}$ reflection bandwidth more compared to the conventional alternating-phase feeding technique. The simulated electric field distributions inside the radiating waveguides at the operating center frequency of $f_{0}$ for both designs are illustrated in Figure 4. As shown in Figure 4(a), the electric field distribution for the conventional alternating-phase feed has an identical phase along the diagonal planes (D-planes). This phase distribution produces the undesirable grating lobes along the D-planes. On the other hand, the simulated electric field of the proposed antenna exhibits the opposite phase distribution with respect to the origin on the D-planes (see Figure 4(b)). The opposite phase discontinuity caused by the proposed hybrid-phase feeding technique facilitates a significant reduction of the grating 


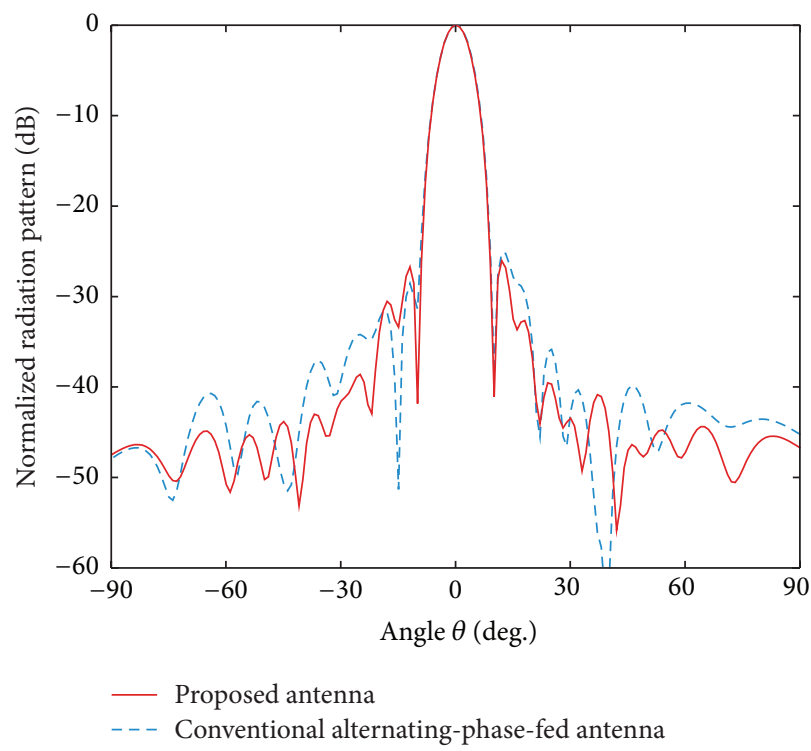

(a)

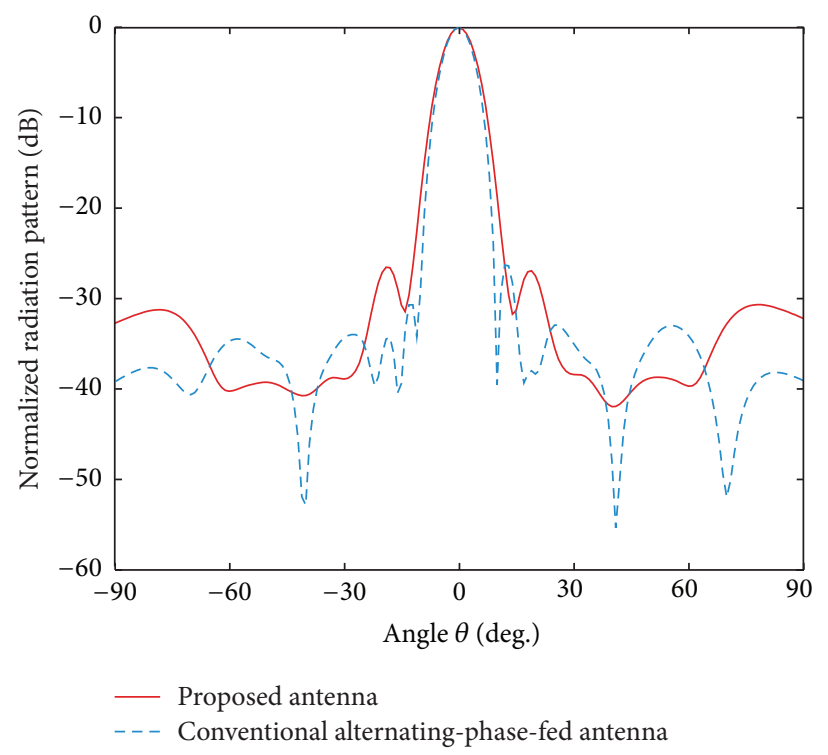

(b)

FIGURE 6: Comparison of simulated normalized radiation patterns at $f_{0}$ between the conventional alternating-phase-fed antenna and the proposed antenna: (a) H-plane and (b) E-plane.

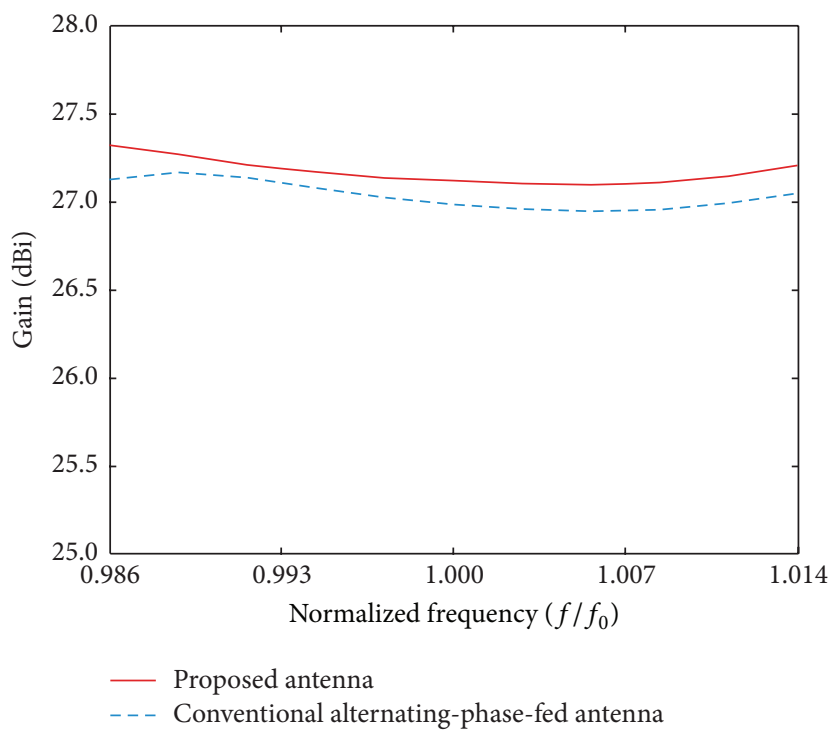

FIGURE 7: Comparison of simulated gains versus the frequency between the conventional alternating-phase-fed antenna and the proposed antenna.

lobes on the D-planes. Figure 5 plots the simulated normalized radiation patterns of the conventional alternatingphase-fed antenna and the proposed antenna at $f_{0}$ on the D-plane $\left(\phi=45^{\circ}\right)$. Although a $25 \mathrm{~dB}$ Chebyshev tapering was applied, the conventional alternating-phase-fed slot array antenna produces a high grating lobe level of $-17.2 \mathrm{~dB}$ at $\theta= \pm 63^{\circ}$. However, the grating lobe level of the proposed waveguide slot array antenna incorporating the hybridphase feed is decreased to $-25.3 \mathrm{~dB}$, which is $8.1 \mathrm{~dB}$ lower than the conventional alternating-phase-fed antenna. The simulated normalized radiation patterns of the conventional alternating-phase-fed antenna and the proposed antenna at $f_{0}$ on the H-plane and E-plane are also illustrated in Figure 6. On the $\mathrm{H}$-plane, the overall radiation patterns of both designs are similar. However, the radiation patterns on the E-plane are different because the cophase feeding scheme is applied to the two center radiating waveguides for the proposed antenna. The sidelobe levels of the proposed hybrid-phase-fed antenna 


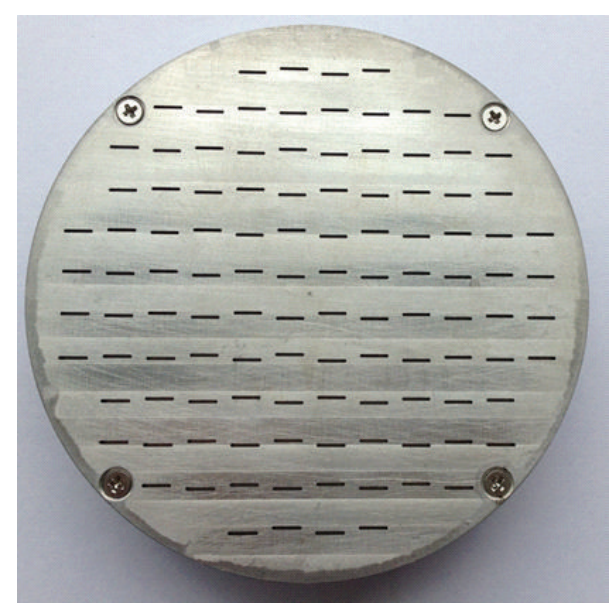

(a)

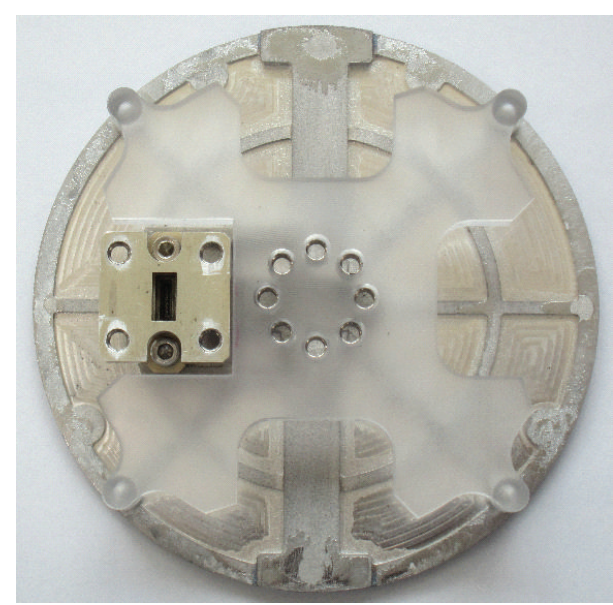

(b)

FIGURE 8: Photograph of fabricated 112-element waveguide slot array antenna with hybrid-phase feed and stepped feed waveguide: (a) front view and (b) back view.

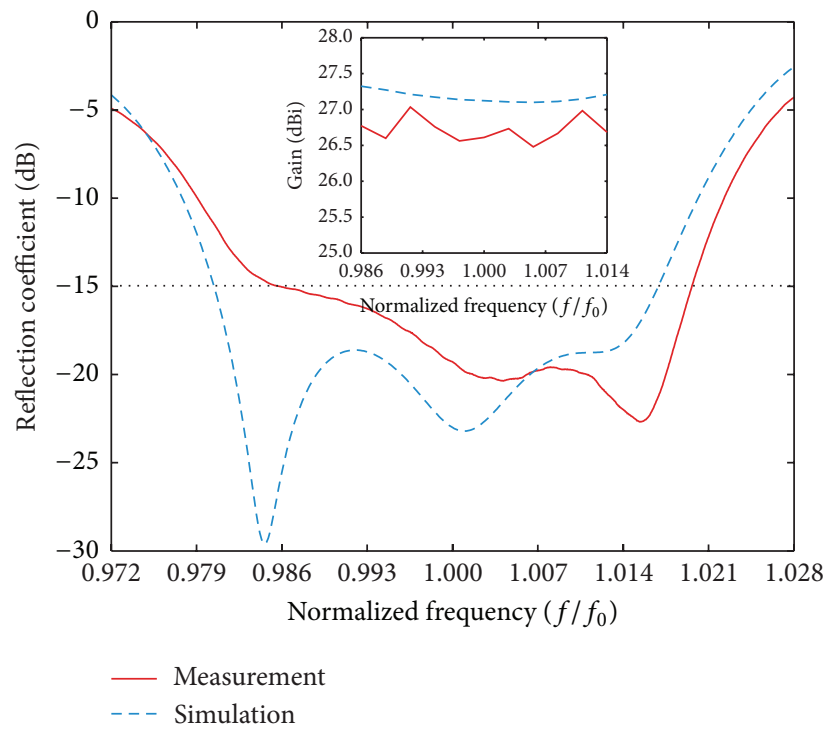

FIGURE 9: Simulated and measured reflection coefficients versus the frequency. The simulated and measured gains versus the frequency are shown in the inset.

are $-26.06 \mathrm{~dB}$ and $-26.45 \mathrm{~dB}$ on the $\mathrm{H}$-plane and E-plane, respectively, whereas the sidelobe levels of the conventional alternating-phase-fed antenna are $-25.25 \mathrm{~dB}$ for the $\mathrm{H}$-plane and $-26.24 \mathrm{~dB}$ for the E-plane. Figure 7 shows the simulated broadside gains versus the frequency within the $-15 \mathrm{~dB}$ reflection bandwidth of the conventional alternating-phasefed antenna and the proposed antenna. The broadside gains of the proposed antenna are slightly higher than those of the conventional alternating-phase-fed antenna.

\section{Fabrication and Experimental Results}

The proposed 112-element waveguide slot array antenna was fabricated and tested. Figure 8 shows an image of the fabricated, brazed waveguide slot array antenna. The results with the simulated and measured reflection coefficients are shown in Figure 9. The simulated and measured $-15 \mathrm{~dB}$ reflection bandwidths are $3.44 \%$ and $3.4 \%$, respectively. Good agreement between the simulation and the measurement results was also achieved. The slight discrepancy between the simulation and measurement is mainly attributed to the fabrication tolerance during the brazing process, which is more sensitive in the millimeter-wave frequency range. Figure 9 also represents the measured result of the antenna gains versus the frequency. An average broadside gain of $26.72 \mathrm{dBi}$ was achieved within the measured frequency range. Figure 10 depicts the simulated and measured normalized radiation patterns at the operating center frequency of $f_{0}$ for 


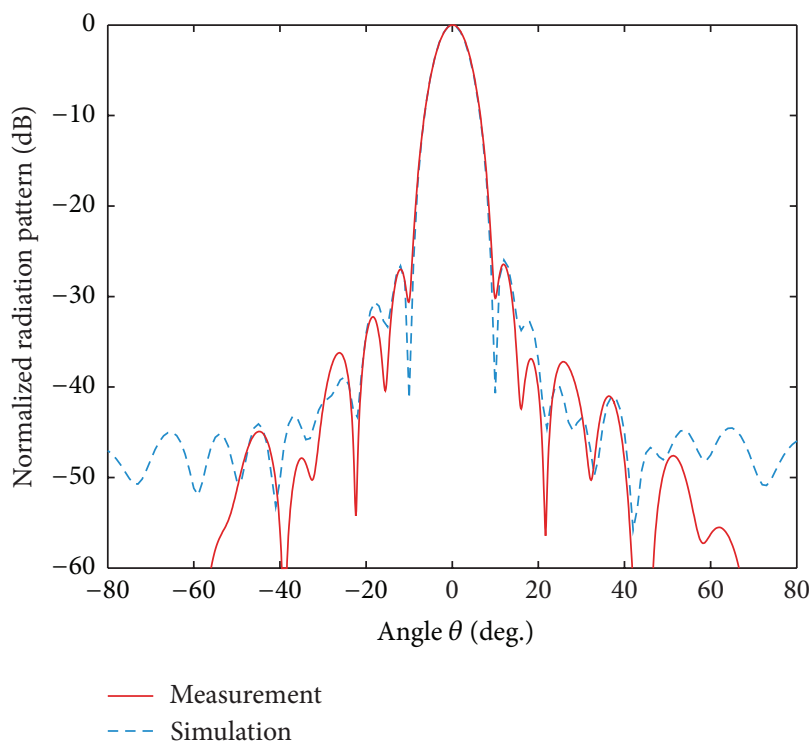

(a)

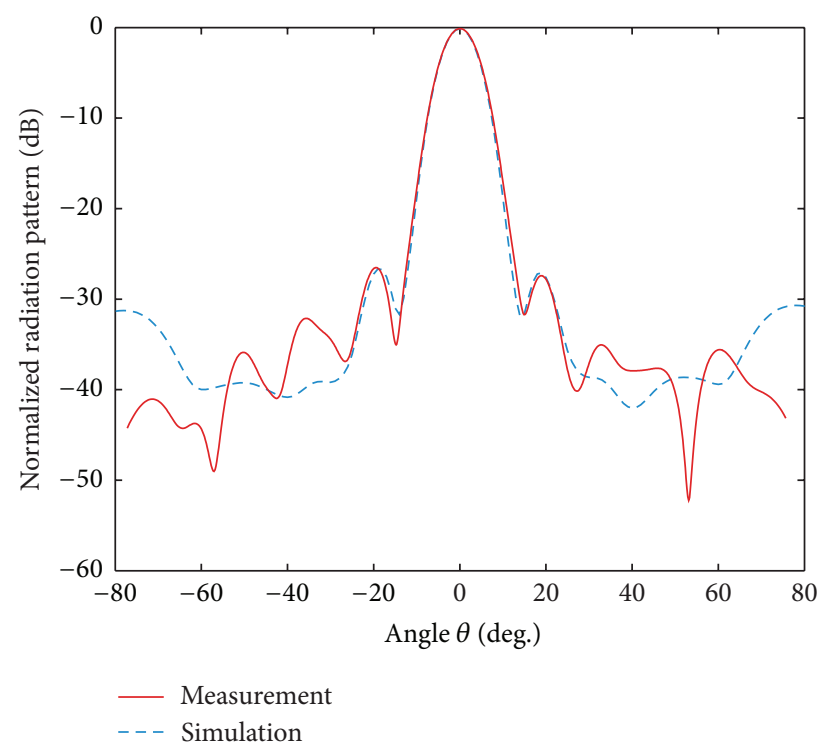

(b)

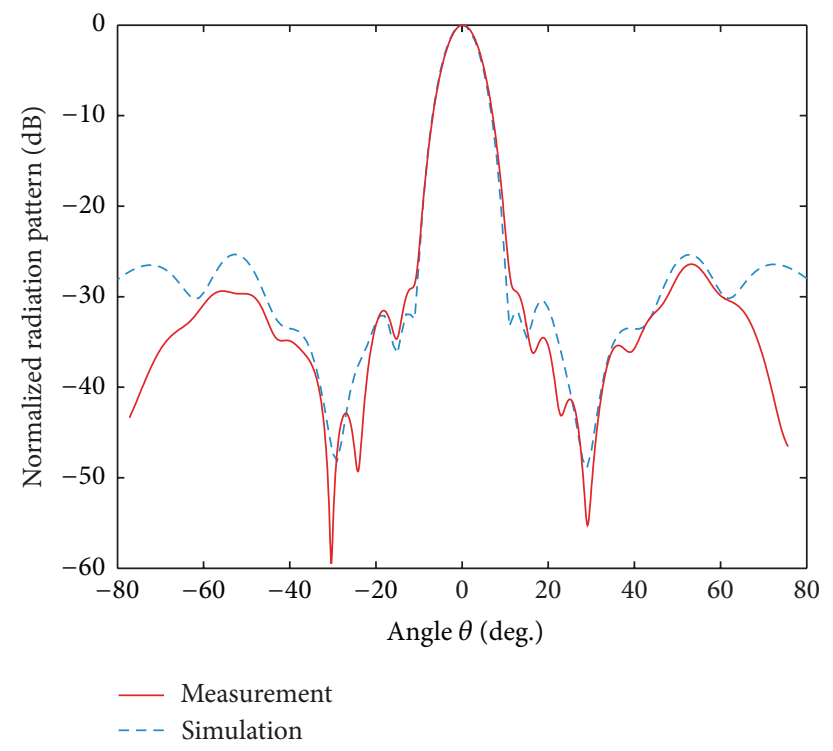

(c)

FIGURE 10: Simulated and measured normalized radiation patterns at $f_{0}$ : (a) H-plane, (b) E-plane, and (c) D-plane.

the H-, E-, and D-planes. The measured results are in good agreement with the simulated results. The measured sidelobe levels are $-26.45 \mathrm{~dB},-26.40 \mathrm{~dB}$, and $-26.41 \mathrm{~dB}$ for the $\mathrm{H}-$, E-, and D-planes, respectively. Figure 11 plots the measured normalized radiation patterns with various frequencies for the $\mathrm{H}-, \mathrm{E}-$, and D-planes. As shown in the figure, low peak sidelobes of less than $-22 \mathrm{~dB}$ were achieved for three different cutting planes within the measured frequency range.

\section{Conclusion}

A 112-element waveguide slot array antenna with a hybridphase feed to suppress the grating lobe was designed, fabricated, and tested in this study. The hybrid-phase feeding technique is utilized to reduce the grating lobe along the diagonal planes. A tapered amplitude distribution is realized by employing a stepped feed waveguide and offset coupling slots aligned in a line. The proposed antenna provides a grating lobe reduction of $8.1 \mathrm{~dB}$ and a low peak sidelobe level of $-26.4 \mathrm{~dB}$ at operating center frequency. A measured $-15 \mathrm{~dB}$ reflection bandwidth of $3.4 \%$ and an average measured gain of $26.72 \mathrm{dBi}$ were also achieved. These results demonstrate that the proposed antenna is an attractive candidate for various satellite communications and military radar systems. 


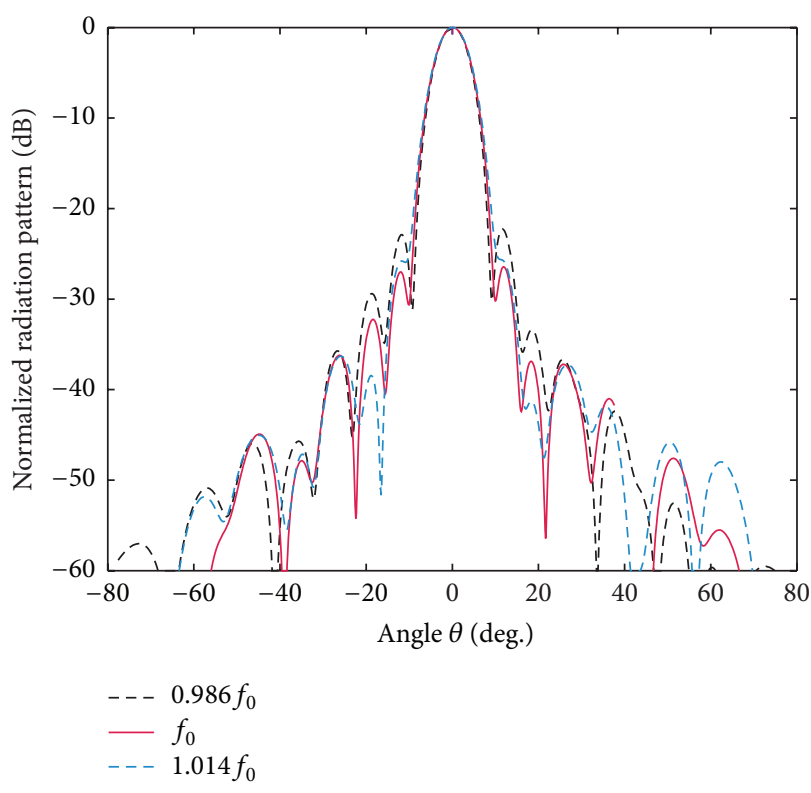

(a)

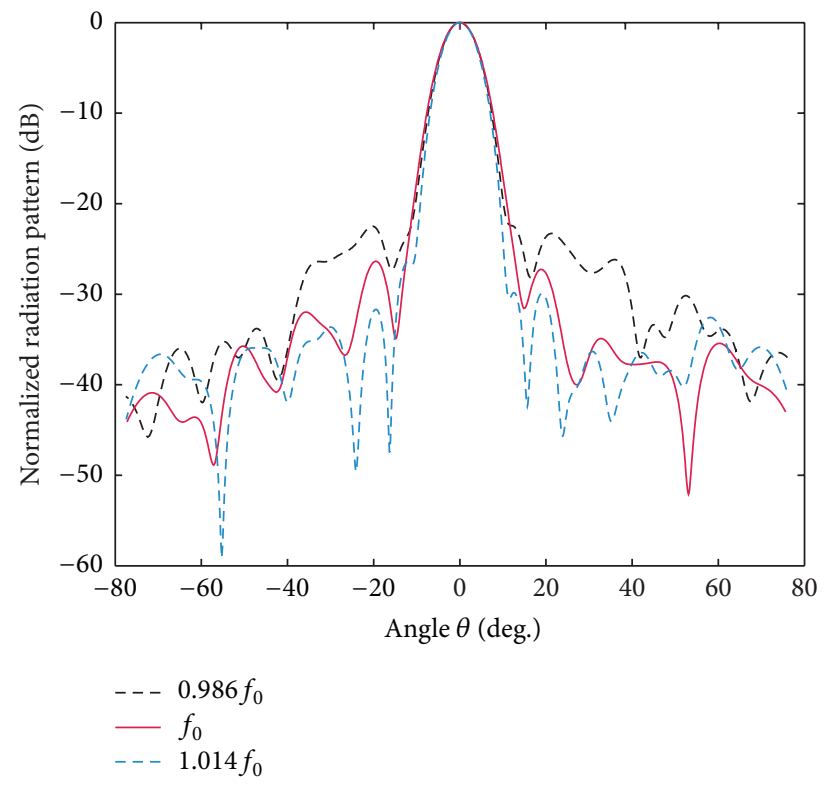

(b)

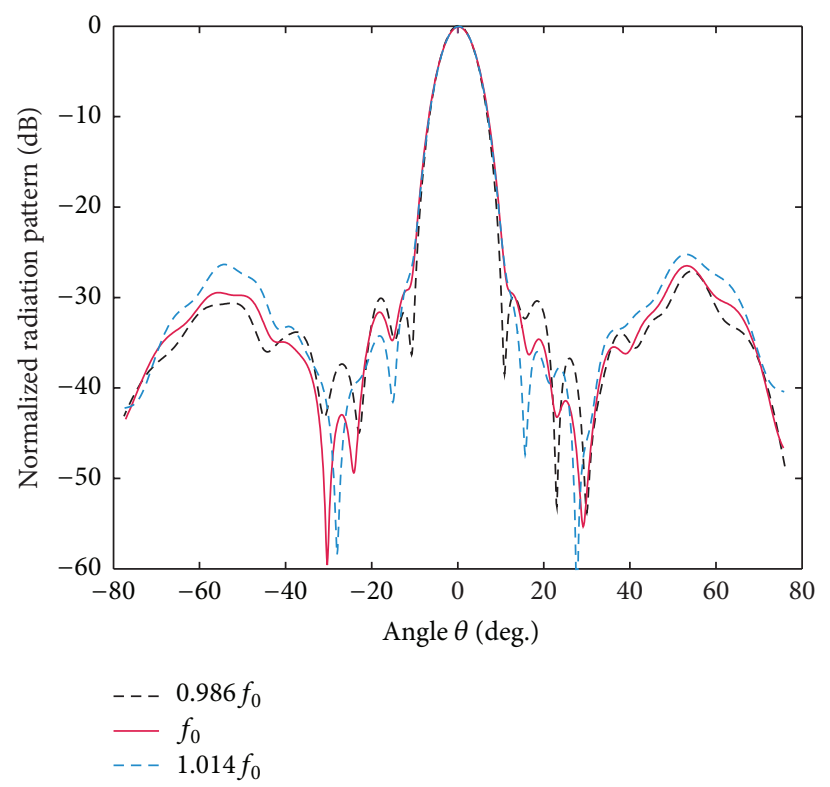

(c)

FIGURE 11: Measured normalized radiation patterns with different frequencies: (a) H-plane, (b) E-plane, and (c) D-plane.

\section{Conflict of Interests}

The authors declare that there is no conflict of interests regarding the publication of this paper.

\section{Acknowledgment}

This work was supported by the research fund of Hanwha Thales.

\section{References}

[1] J.-H. Hwang and Y. Oh, "Millimeter-wave waveguide slot-array antenna covered by a dielectric slab and arrayed patches," IEEE Antennas and Wireless Propagation Letters, vol. 8, pp. 1050-1053, 2009.

[2] J. $\mathrm{Xu}, \mathrm{Z} . \mathrm{N}$. Chen, and X. Qing, "CPW center-fed singlelayer SIW slot antenna array for automotive radars," IEEE Transactions on Antennas and Propagation, vol. 62, no. 9, pp. 4528-4536, 2014. 
[3] D.-Y. Kim, Y. Lim, H.-S. Yoon, and S. Nam, "High-efficiency Wband electroforming slot array antenna," IEEE Transactions on Antennas and Propagation, vol. 63, no. 4, pp. 1854-1857, 2015.

[4] R. S. Elliott and L. A. Kurtz, "The design of small slot arrays," IEEE Transactions on Antennas and Propagation, vol. 26, no. 2, pp. 214-219, 1978.

[5] R. S. Elliott, "An improved design procedure for small arrays of shunt slots," IEEE Transactions on Antennas and Propagation, vol. 31, no. 1, pp. 48-53, 1983.

[6] R. S. Elliott and W. R. O'Loughlin, “The design of slot arrays including internal mutual coupling," IEEE Transactions on Antennas and Propagation, vol. 34, no. 9, pp. 1149-1154, 1986.

[7] M. Hamadallah, "Frequency limitations on broad-band performance of shunt slot arrays," IEEE Transactions on Antennas and Propagation, vol. 37, no. 7, pp. 817-823, 1989.

[8] J. C. Coetzee, J. Joubert, and W. L. Tan, "Frequency performance enhancement of resonant slotted waveguide arrays through the use of wideband radiators or subarraying," Microwave and Optical Technology Letters, vol. 22, no. 1, pp. 35-39, 1999.

[9] B. Svensson, G. Snygg, and P. Holmberg, "A low cost, high performance point-to-point slotted waveguide array," Microwave Journal, vol. 42, no. 11, pp. 1-5, 1999.

[10] S.-S. Oh, J.-W. Lee, M.-S. Song, and Y.-S. Kim, “Two-layer slotted-waveguide antenna array with broad reflection/gain bandwidth at millimetre-wave frequencies," IEE ProceedingsMicrowaves, Antennas and Propagation, vol. 151, no. 5, pp. 393398, 2004.

[11] S. R. Rengarajan, M. S. Zawadzki, and R. E. Hodges, "Bandwidth enhancement of large planar slot arrays," in Proceedings of the Antennas and Propagation Society International Symposium, pp. 4405-4408, IEEE, Honolulu, Hawaii, USA, June 2007. 


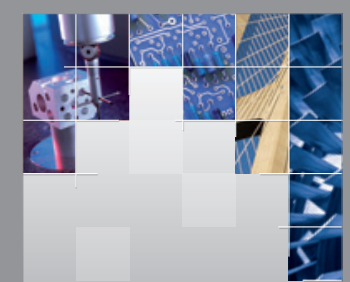

\section{Enfincering}
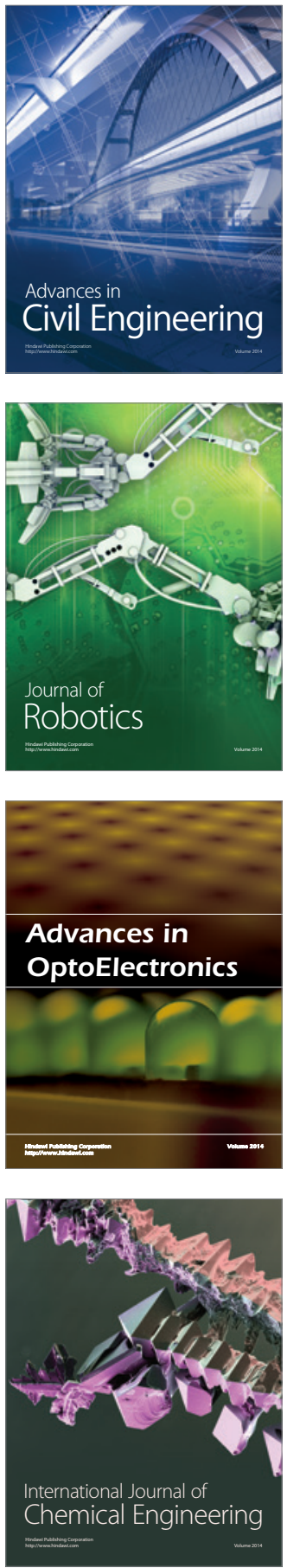

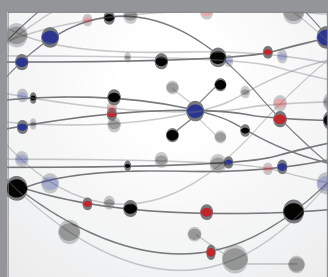

The Scientific World Journal

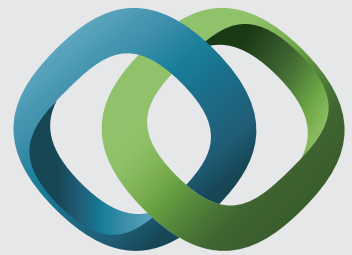

\section{Hindawi}

Submit your manuscripts at

http://www.hindawi.com
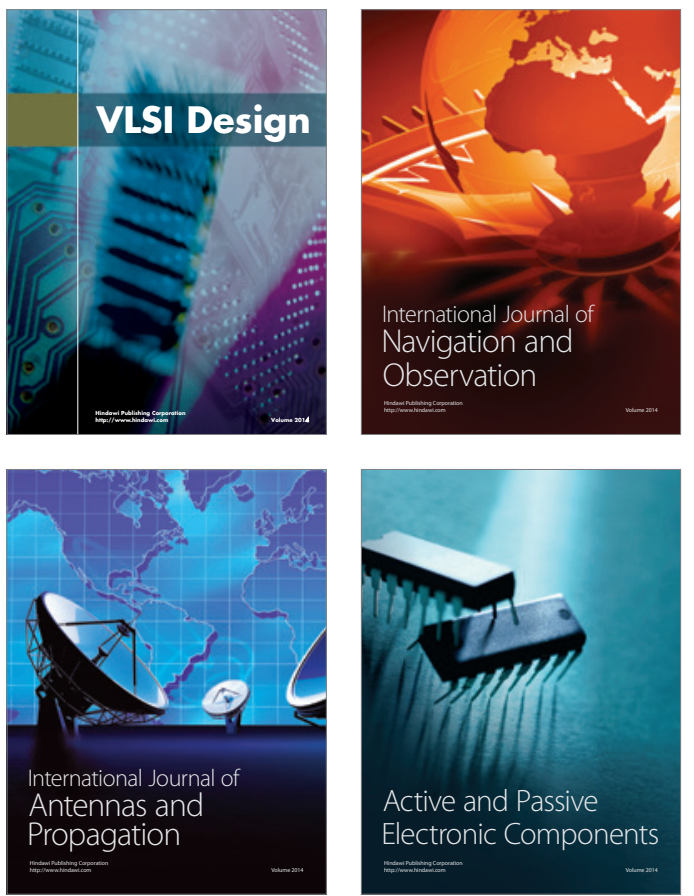
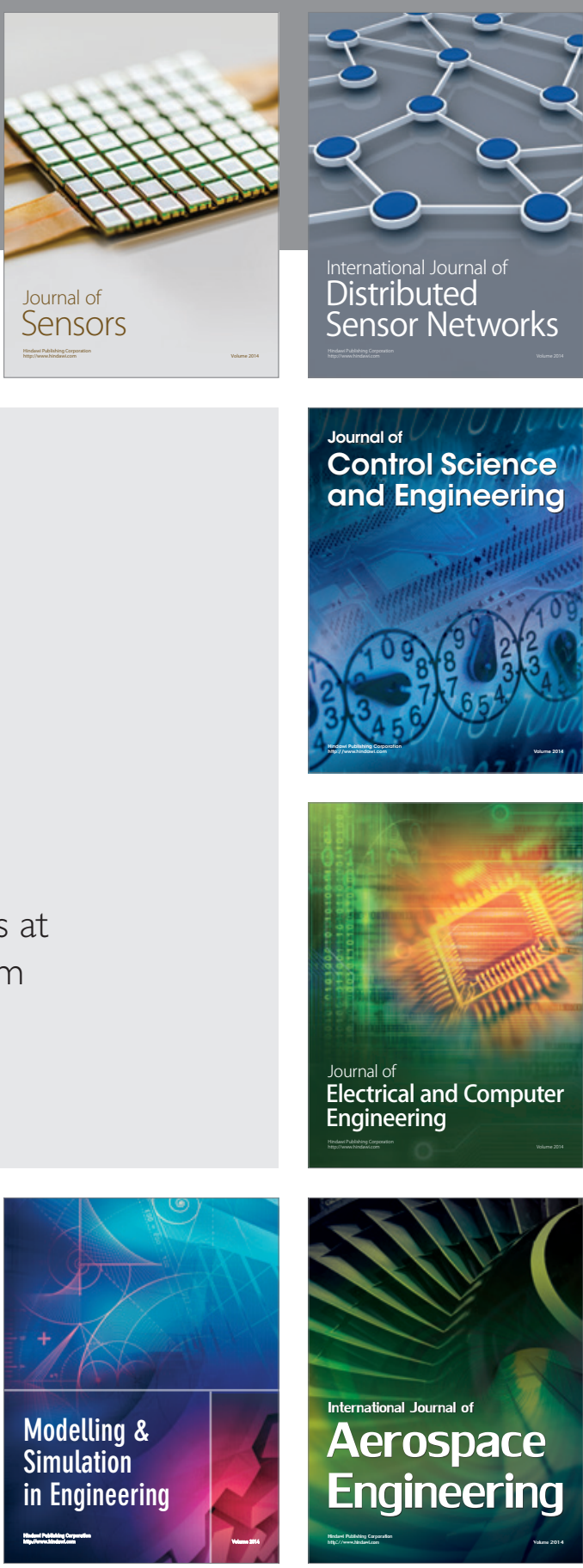

International Journal of

Distributed

Sensor Networks

Journal of

Control Science

and Engineering
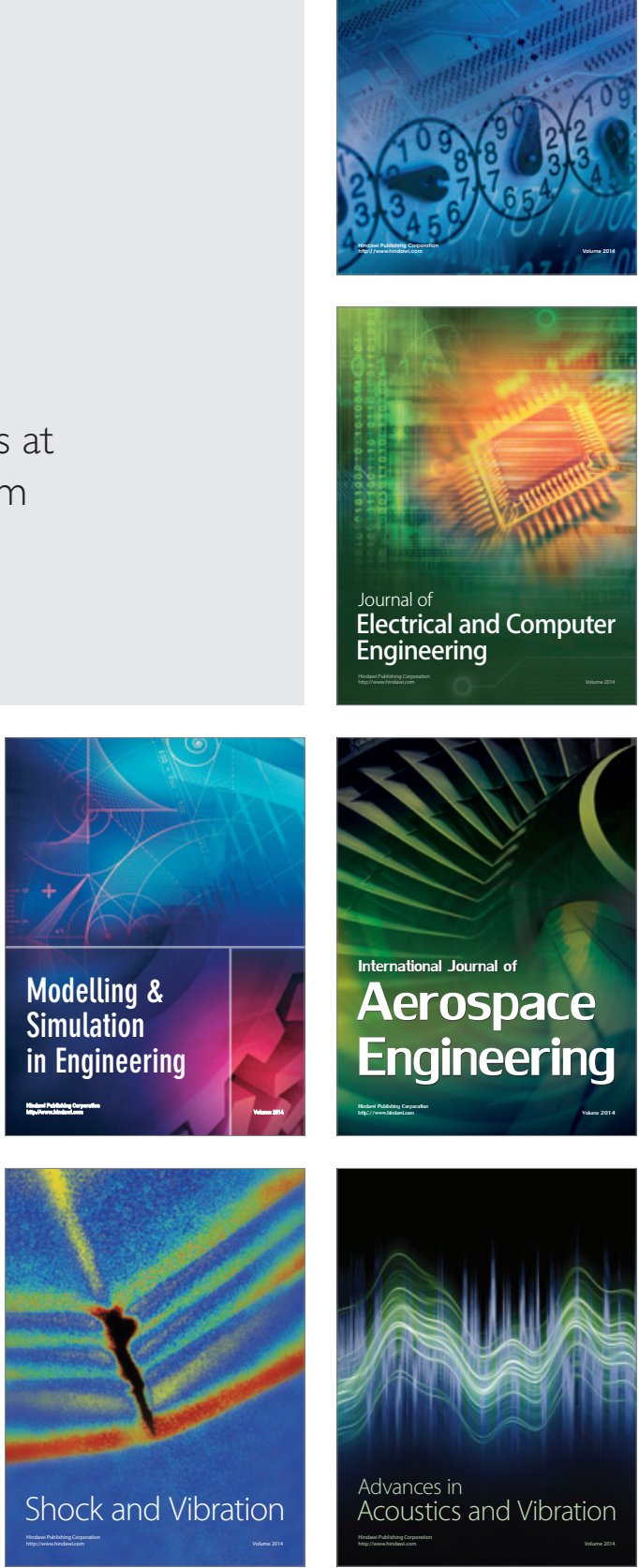